\title{
O CURSO DE ARQUEOLOGIA DA UFPE E A PROFISSÃO DE ARQUEÓLOGO
}

Carlos Rios*

Marilia Perazzo**

* Departamento de
Arqueologia da
Universidade Federal de
Pernambuco - UFPE.
** Fundação Paranã-buc

RESUMO: O Projeto de Extensão da UFPE intitulado "O Curso de Arqueologia e a Profissão do Arqueólogo" vem sendo desenvolvido desde 2011 e já atuou em mais de 50 escolas do Grande Recife, sejam públicas ou privadas. O cerne do Projeto é levar para os alunos do último ano do Ensino Médio informações acerca da profissão do arqueólogo e de como funciona o Curso de Arqueologia da UFPE. É importante a execução desse Projeto, pois permite ao aluno que está prestes a escolher sua profissão, desmistificar e compreender de forma didática e sistemática quais as atribuições de um arqueólogo, como seu trabalho pode e deve ser executado e, sobretudo, a sua importância social. No decorrer da execução deste Projeto já foi possível verificar seus resultados positivos para o Curso de Arqueologia da UFPE, uma vez que, anualmente, $10 \%$ dos alunos que ingressam são oriundos das escolas onde o projeto foi executado.

Palavras-chave: Curso de Arqueologia; Extensão; Profissão de Arqueólogo; UFPE

ABSTRACT: The UFPE Extension Project entitled "O Curso de Arqueologia e a Profissão do Arqueólogo" has been developed since 2011 and has worked in more than 50 schools in Greater Recife, whether public or private. The heart of the Project is to provide high school seniors with information about the archaeologist's profession and how the UFPE Archeology Course works. It is important to carry out this Project, since it allows the student who is about to choose his profession, demystify and comprehend in a didactic and systematic way the duties of an archaeologist, how his work can and should be performed and, above all, its social importance . During the execution of this Project, it was already possible to verify its positive results for the UFPE Archeology Course, since, annually, $10 \%$ of the students who enter are from the schools where the project was executed.

Key words: Archeology Course; Extension; Archaeologist Profession; UFPE 


\section{Introdução}

Em se tratando do seu significado etimológico, Arkhaiologia, Arqueo, do grego quer dizer antigo, enquanto que Logus, Logos remete a estudo, assim de uma maneira simples, Arqueologia significa o estudo das antiguidades (Houaiss e Villar, 2001). De uma forma mais erudita, Arqueologia é uma ciência social que estuda o homem por meio da análise e interpretação dos seus restos materiais, ou seja, a sua cultura material em seus devidos contextos (Rambelli, 2000). Entende-se por cultura material todos os artefatos produzidos pelo homem, bem como contexto, no presente caso, significa que os artefatos ou vestígios têm uma relação estreita entre si na composição do sítio.

No Brasil os primeiros trabalhos descritivos, alusivos a Arqueologia, foram de ordem etnográfica, desenvolvidos por Gabriel Soares de Sousa, em 1587, agricultor e empresário português, em sua obra Tratado Descritivo do Brasil, falando sobre os Guaianazes e suas casas subterrâneas. Em seguida, em 1598, Feliciano Coelho de Carvalho, português, capitão-mor da Capitania da Paraíba, em sua viagem pelo sertão de Copaoba (PB),encontra algumas inscrições rupestres que depois são relatadas por Ambrósio Fernandes Brandão, em seu livro Diálogo das Grandezas do Brasil, em 1618.

Já no século XVII, em 1601, o padre jesuíta português Fernão Cardim disserta sobre sambaquis, em seu livro Tratado da terra e gente do Brasil, em 1625. Por sua vez, Yves d’Evreux, um religioso e entomólogo francês, em 1615, fala sobre os machados semilunares dos Tapuias, em seu livro Viagem ao Norte do Brasil (Maranhão). Já Albert Eckhout, artista plástico holandês, retratou os propulsores dos indígenas pernambucanos (Caetés), em sua pintura intitulada Tapuia, entre 1641 e 1643.

No século XIX alguns eruditos e viajantes passam a vir para o Brasil, dentre eles Peter Wilhelm Lund, médico e naturalista dinamarquês, decidiu estabelecer residência em Lagoa Santa, MG, e estudou uma grande quantidade de fósseis encontrados nas centenas de cavernas entre Sabará e Curvelo, tendo se dedicado também às pesquisas arqueológicas. Em 1843 encontrou na região vestígios de homens pré-históricos que ficaria conhecido, posteriormente, como o Homem de Lagoa Santa (Marchesoti, 2011).

Ainda no século XIX, Carl Friedrich Philipp Von Martius médico, botânico e antropólogo, foi um importante pesquisado alemão que estudou as regiões norte e nordeste do país. Em seu trabalho Viagem pelo Brasil descreve, detalhadamente, os costumes e características de diferentes tribos brasileiras, também fala sobre as línguas usadas por cada tribo. Martius faz 
uma tentativa de classificar as diferentes tribos, demonstrando sua visão etnocentrista, colocando os índios em uma posição inferior ao homem europeu.

Augustin François César Prouvençal Saint-Hilaire foi um naturalista e viajante francês. Fez parte de um dos primeiros grupos de cientistas europeus para realizar suas pesquisas e explorações no Brasil Colônia, entre os anos de 1816 e 1822, tendo escrito importantes livros sobre os costumes e paisagens brasileiros do século XIX.

Neste contexto, a Arqueologia no Brasil começou a ser praticada pelos naturalistas, paleontólogos, médicos, antropólogos e viajantes estrangeiros, no segundo quartel do século XIX, com estudos sobre a Pré-história, ora de forma científica, ora de maneira fantasiosa, tendo como foco gravuras e pinturas rupestres, bem como os sambaquis do litoral, principalmente no sul e sudeste (Martin, 2008).

Entre o final do século XIX e primeiro quartel do século XX a Arqueologia no Brasil deixou de ser desenvolvida de forma insipiente, por amadores, para ter os primeiros brasileiros atuando de forma científica, surgindo nomes como Ladislau de Souza Mello Netto, brasileiro, botânico, diretor do Museu Nacional (1885), Emílio Augusto Goeldi, suíço-alemão, naturalista e zoólogo, (188-1900), Edgar Roquette Pinto, brasileiro, médico, antropólogo, etnólogo dentre outros, bem como chegam ao Brasil os primeiros arqueólogos estrangeiros para efetuar trabalhos, tais como: A. Padberg-Drenkpohl (austríaco) e A. Serrano (argentino).

Nos dois primeiros quartéis do século $\mathrm{XX}$ a arqueologia brasileira ainda trabalhava com amadores ou profissionais oriundos do exterior. As publicações, em sua grande maioria, eram feitas por estrangeiros, com raras exceções, como o Manual de Arqueologia escrito por Angyone Costa. Dos anos 50 em diante o Brasil passou a ter uma legislação própria e missões estrangeiras passaram a incorporar brasileiros em seus trabalhos, bem como o Estado desenvolveu projetos como o Programa Nacional de Pesquisas Arqueológicas - Pronapa e o Programa Nacional de Pesquisas Arqueológicas da Bacia Amazônica - Pronapaba, formando brasileiros nos misteres da Arqueologia (Martin, 2008).

O primeiro curso de Arqueologia no Brasil começou na cidade do Rio de Janeiro, RJ, na década de 70 do século passado, na Faculdade de Arqueologia e Museologia Marechal Rondon (FAMARO) que, segundo a pesquisadora Márcia Bezerra, antes de completar um ano de existência, foi absorvido pelas Faculdades Integradas Estácio de Sá (Fines), tendo formado até 1996, 206 alunos, cujos professores eram oriundos, principalmente, da Antropologia e da História (Bezerra, 2008). 
A Universidade Federal de Pernambuco tomou o caminho inverso do que se espera de um curso, ou seja, ter início com a Graduação para depois enveredar na Pós-Graduação. Assim, por iniciativa de alguns professores que trabalhavam no Departamento de História, do Centro de Filosofia e Ciências Humanas, o Curso de Pós-Graduação em Arqueologia e Conservação do Patrimônio teve lugar a partir de 2002, contando com professores, com formação, mormente na área das Ciências Humanas, bem como com professores visitantes, nacionais e estrangeiros de outras universidades do Brasil e do exterior.

Com o advento de leis, normas e portarias, mormente a partir dos anos 1960,voltadas para a Arqueologia tanto em terra quanto em ambientes aquáticos, tais como asLeis Federais $\mathrm{n}^{\circ}$ 3.924/61; $n^{\circ} 7.542 / 86$, alterada pela $n^{\circ} 10.166 / 00$, a Portaria do Ibama $n^{\circ} 01 / 86$; a Portaria do Iphan $n^{\circ}$ 07/88 e Portaria $n^{\circ}$ 69/89e do então Ministério da Brasil, em conjunto com 0 Ministério da Educação e Cultura; a Instrução Normativa do Iphan $n^{\circ}$ 01/15 criou um arcabouço jurídico que, associado ao Programa de Aceleração do Crescimento (PAC) do Governo Federal, fez com que as obras existentes passassem a ter arqueólogos, dentre outros profissionais, vislumbrando um novo viés denominado Arqueologia de Contrato.

Como consequência da nova conjuntura desenvolvimentista, os cursos de Arqueologia tiveram um crescimento considerável no início do século XXI, isto porque o horizonte de trabalhou permeou as três esferas governamentais e abriu nichos em várias áreas das ciências humanas, bem como de empresas de engenharia e arquitetura voltadas para a construção civil.

No Brasil, até dezembro de 2017, existem 12 (doze) cursos de Graduação em Arqueologia, ou seja, bacharelado, não há licenciatura. O primeiro foi implantado em 2005, na Universidade Federal do Vale do São Francisco - Univasf, em Petrolina, PE, cujo curso de Arqueologia e Preservação Patrimonial funciona em São Raimundo Nonato, PI. As graduações em Arqueologia são: Pontifícia Universidade Católica de Goiás (PUC-GO), Fundação Universidade Federal de Rondônia (UNIR), Universidade Federal do Rio Grande (FURG), Universidade Federal de Pernambuco (UFPE), Universidade Federal do Sergipe (UFS), Universidade Federal do Piauí (UFPI),Universidade do Estado do Amazonas (UEA), Universidade do Estado da Bahia (UNEB), Universidade Federal do Oeste do Pará (UFOPA), Universidade Federal do Rio de Janeiro (UERJ) e Universidade Metropolitana de Santos (UNIMES).

O título do presente artigo diz respeito a um trabalho de extensão que vem sendo realizado pelo Departamento de Arqueologia da UFPE, desde 2011. Este projeto foi idealizado em virtude do desconhecimento de um percentual significativo dos alunos (20\%) que estavam 
ingressando no Curso de Graduação em Arqueologia, acerca do curso e da profissão que estavam por iniciar. No início a nota de corte no vestibular estava na casa dos 3,4 , o que também incentivava alguns alunos a se inscreverem apenas como forma de adentrar em uma Universidade pública acreditando ser esta a chance de concluir o Ensino Superior.

Neste contexto, após diálogos e preenchimento de uma rotina individual de cada aluno que ingressava por ano no curso, na disciplina de Arqueologia Brasileira, observou-se que esse percentual de interessados em trilhar a referida área das Ciências Humanas, apesar de toda a informação disponível na mídia, inclusive no Portal da UFPE, tinha uma ideia equivocada do que era Arqueologia, bem como da profissão de Arqueólogo.

A UFPE forma profissionais nas diversas áreas da Arqueologia, com ênfase na Conservação e Restauração do Patrimônio Arqueológico. Os professores têm formação diversificada, existindo desde formação em Ciências Exatas e da Natureza (Engenharia, Geologia, Física e Química), passando pelas Ciências da Natureza (Biologia) e Ciências Humanas (Arqueologia, Arquitetura, Antropologia, Geografia, História e Sociologia).

O Curso tem um universo de 30 candidatos/ano, em uma única entrada, cuja aprovação ocorreu em 2008 e teve início em 2009. Ocupam os dois turnos (manhã e tarde), mas algumas disciplinas eletivas podem ser oferecidas no período noturno. Possui uma carga horária de 3.270 horas, tem duração mínima de 4 anos (8 semestres) e máxima de 7 anos (14 semestres).As disciplinas são, normalmente, oferecidas em módulos, o que permite a participação do aluno em pesquisas de campo e escavações a cada semestre.

O Curso de Bacharelado em Arqueologia responde a uma necessidade do país para dispor de profissionais que possam se responsabilizar pela guarda, conservação, restauração e pesquisa do patrimônio arqueológico e cultural do país. O Arqueólogo atua como agente de conservação na preservação do patrimônio cultural em órgãos municipais, estaduais e federais, faz pesquisa e ensino em universidades, fundações e institutos, bem como realiza trabalhos de consultoria, relatórios, projetos, perícias e pareceres em escritórios, firmas e empresas particulares.

A Arqueologia é uma área de convergência que necessita da participação de outros ramos da ciência, tanto para a incorporação de resultados multidisciplinares como na participação de pesquisadores em trabalhos compartilhados. Formado nas técnicas de pesquisa e escavação, 0 arqueólogo recebe a colaboração essencial de numerosos cientistas de outras áreas que analisam, restauram e conservam os bens culturais. 
A grade curricular é diversificada, existindo uma gama enorme de assunto que não são oferecidos nas demais universidades do resto do País, tais como: Metrologia Arqueológica, Arqueomática, Estatística Aplicada a Arqueologia, Geoarqueologia, Conservação Patrimonial, Carta Arqueológica de Naufrágios, Arqueoturismo Subaquático, Fatores Causadores de Naufrágios, Arqueologia Forense, Balística Forense e Saúde e Segurança Ocupacional de Arqueologia.

Desde a sua criação até 2017 já ingressaram 267, se formaram 56 alunos, dos quaisa grande maioria trabalha em Arqueologia. Na atualidade, existem 118 alunos matriculados na graduação, cuja taxa de reprovação é de $47 \%$ e desistência gira em torno de $35 \%$.

No tocante a Pós-Graduação, de 2002 até 2017 já se formaram 89 mestres, 25 doutores e 4 Pós-Doutores. Na atualidade a Pós-Graduação conta com 36 mestrandos, 22 doutorandos e 1 Pós-Doutorando. Os discentes tem origem variada, existindo Arqueólogos, Arquitetos, Artistas Plásticos, Biólogos, Geógrafos, Historiadores, Museólogos e Sociólogos.

Dentre outras facilidades, o curso oferece a possibilidade de publicação de artigos, resenhas e relatórios na Revista Clio Arqueológica semestral, que está classificada como B1 pela Capes, biblioteca especializada no andar de trabalho, possibilidades de bolsas de estudo, uso dos laboratórios de Arqueologia da UFPE (Laboratório de Estudos Arqueológicos - LEA; Laboratório de Arqueologia para Conservação e Restauro - LACOR; Laboratório de Arqueologia Biológica e Forense - LABIFOR; Núcleo de Estudos Arqueológicos - NEA; Laboratório de Arqueologia Subaquática - LABARQS e Laboratório de Educação Patrimonial - LEDUP) e apoio logístico em trabalhos de campo.

No que diz respeito ao mercado de trabalho, quase todos os arqueólogos estão empregados. 0 mercado de trabalho, mormente a Arqueologia de Contrato, absorve 95\% da demanda.

\section{O Desenvolvimento do Projeto}

O trabalho de Extensão foi desenvolvido em 2011, com objetivo principal de divulgar o Curso de Bacharelado em Arqueologia da UFPE. As atividades realizadas consistem em palestras proferidas em escolas do Ensino Médio do Grande Recife.

No princípio, o coordenador ia a cada escola escolhida, na razão de 50\% particulares e $50 \%$ públicas, em diversos bairros da cidade do Recife, tendo como público alvo os alunos que iriam prestar vestibular, apresentando folders e banners elaborados para o desenvolvimento do projeto, para a direção das referidas escolas que, por sua vez achava interessante, mas nem 
todos marcavam a palestra e o índice de realização do trabalho era de 50\%. No ano seguinte aconteceu a mesma coisa. O número de alunos/ano que ingressavam no curso após a execução do projeto era igual a 1.

Para facilitar o diálogo com as escolas da rede pública de ensino foi contatada a Secretaria de Educação do Estado de Pernambuco, onde foi solicitado o auxílio para agendar, nas escolas de Ensino Médio, data/hora para realização das palestras. A direção pedagógica fazia o contato com as escolas da rede pública que têm, em cada sala de aula, um mínimo de 30 e um máximo de 60 alunos.

A Secretaria de Ensino escolheu Escolas de Referência do Ensino Médio - EREM, bem como Escolas Técnicas do Grande Recife e ainda colocou para acompanhar os trabalhos uma pedagoga. A partir de 2014 foi possível proferir 10 palestras/ano e o número de alunos que ingressaram nas fileiras da Arqueologia passou para 3, ou seja, 10\% das vagas disponíveis do Curso.

As palestras proferidas (Foto 01, 02) além de informar dados acerca do curso de Bacharelado em Arqueologia da UFPE aborda a profissão do arqueólogo, permitindo aos alunos do Ensino Médio compreender, de forma sistemática, as atribuições do profissional de arqueologia no campo e no laboratório. Foi observado durante o desenvolvimento deste projeto que a grande maioria dos expectadores não conhecia a referida profissão e, como exemplo, muitos não sabiam sequer a diferença entre arqueólogo e paleontólogo.

Para facilitar a didática das apresentações foram elaborados banners, bem como foram impressos folders contendo informações sobre o Curso de Arqueologia e a profissão de Arqueólogo. As palestras possuem duração de 1 hora e ao final os alunos podem debater com o palestrante, momento este de extrema importância, uma vez que as dúvidas acerca do tema são esclarecidas. 


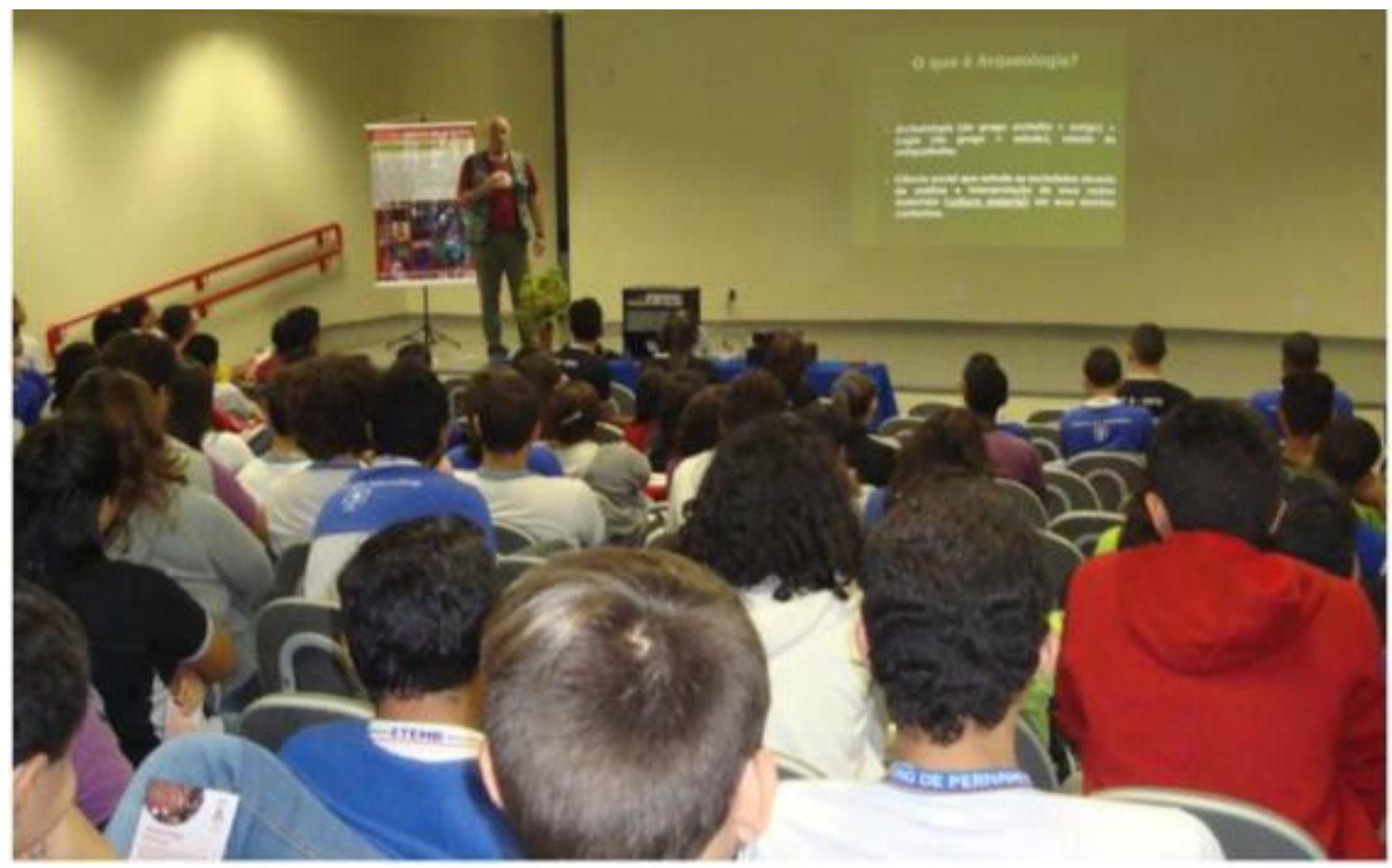

Figura 1: Escola Técnica Estadual Maximiano Campos. Acervo particular, 2016.

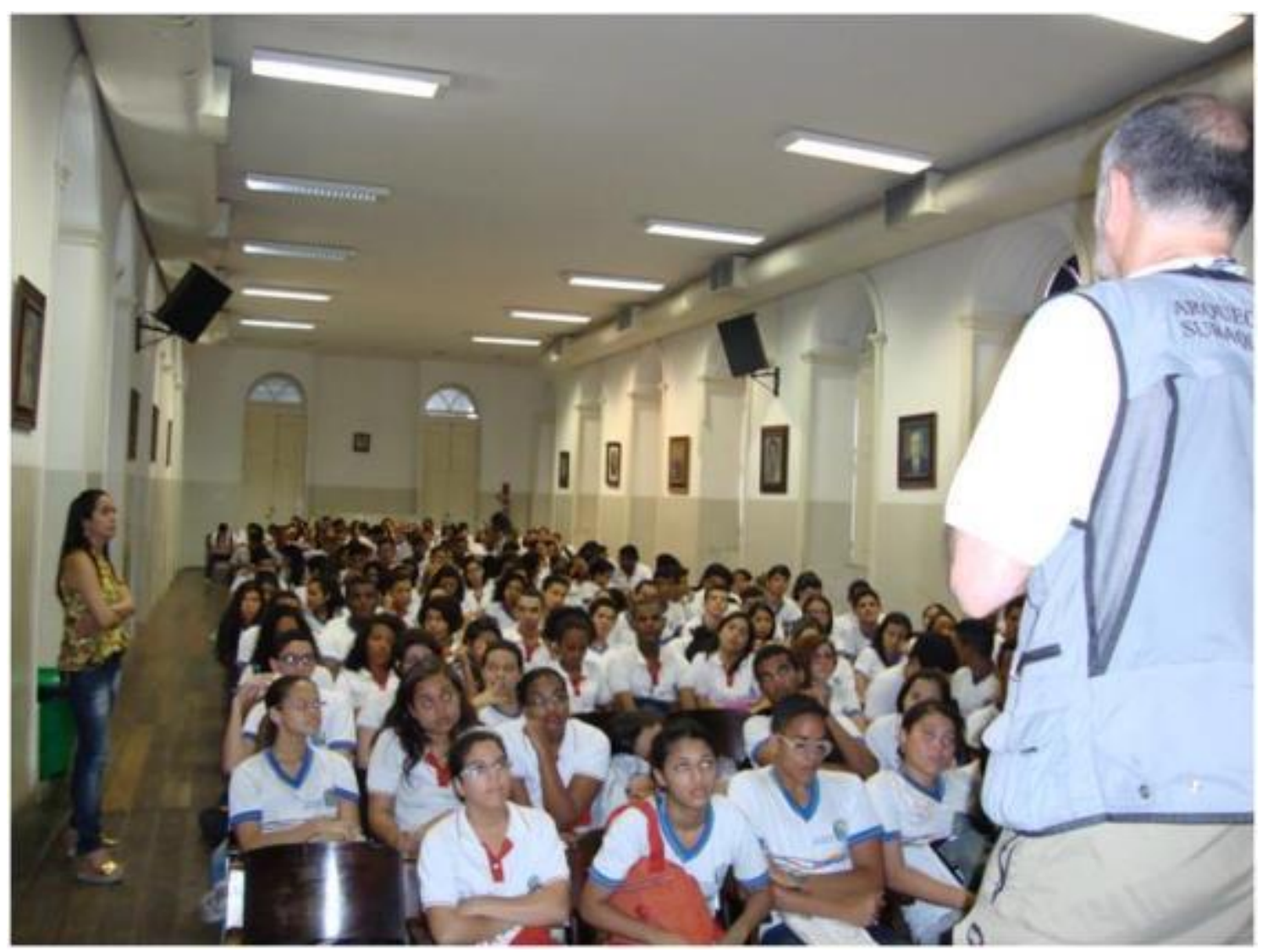

Figura 2: Ginásio Pernambucano. Acervo particular, 2015. 
Este projeto vem, no decorrer dos sete anos de execução, ganhando força uma vez que o número de espectadores vêm aumentando consideravelmente. Em 2018 a estimativa de público é de 1.500 alunos, o que pode vir a acarretar em um número maior de candidatos para concorrer às vagas oferecidas para o curso, cujo ponto de corte em 2017 foi de 6,22.

Além das escolas do Grande Recife este Projeto está sendo apresentado em outro município pernambucano na Zona da Mata. Graças ao convênio firmado pela Fundação Paranã-buc com Instituto Histórico e Geográfico de Vitória de Santo Antão (IHGVSA) está sendo possível replicar este projeto nas escolas de Ensino Médio do referido município. Outros convênios estão sendo firmados com instituições de Ensino e Pesquisa do Agreste Pernambucano, o que vai possibilitar expandir este Projeto, ampliando, dessa forma, o conhecimento acerca da Arqueologia em Pernambuco e da importância do curso de graduação em Arqueologia da UFPE.

\section{Referências}

BEZERRA, M. Bicho de Nove Cabeças: os cursos de graduação e a formação de arqueólogos no Brasil, In: Revista de Arqueologia. SAB. Belém, 21, n. 2:139-154,

BRANDÃO, A. F. Diálogo das Grandezas do Brasil. Recife: Massangana, 1997.

CARDIM, F. Tratado da terra e gente do Brasil. São Paulo: Hedra, 2009.

HOUAISS, A. e VILLAR, M. S. Dicionário Houaiss da Língua Portuguesa. Rio de Janeiro: Objetiva, 2001.

MARCHESOTTI, A. P. A.Peter Wilhelm Lund - o naturalista que revelou ao mundo a pré-história brasileira. Rio de Janeiro: E-papers serviços editoriais Ltda,2011.

MARTIN, G. Pré-História do Nordeste do Brasil. Recife: Editora da UFPE, 2008.

RAMBELLI, G. Arqueologia até debaixo d'água. São Paulo: Maranta, 2002.

SEDA, P.; BEZERRA, M. Formação de Arqueólogos no Brasil: O Bacharelado em Arqueologia, In: SOUZA, S. (org.) Anais do IX Congresso da Sociedade de Arqueologia Brasileira (CD Room). SAB. Rio de Janeiro, 2000.

SPIX, J. B.; MARTIUS, C. F. P. Viagem pelo Brasil 1817-1820. São Paulo: Melhoramentos, 1981.

D’EVEREUX, Y. Viagem ao Norte do Brasil. São Paulo: Siciliano, 2002.

GOVERNO FEDERAL. Disponível em www.emec.mec.gov.br Acesso em 20.01.2018.

GOVERNO FEDERAL. Disponível em www.mec.gov.br Acesso em: 13.01.2018. 
BRASIL. Portaria do SPHAN $\mathrm{n}^{\circ} 07$ de 01 de Dezembro de 1988, que regulamenta os pedidos de permissão para desenvolvimento de pesquisas de campo e escavações arqueológicas. Diário Oficial [da] República Federativa do Brasil, Brasília, DF, 15 dez. 1988.

2008.

SOUSA, G, S. Tratado Descritivo do Brasil. São Paulo: Hedra, 2010.

BRASIL. Resolução do CONAMA nº1 de 23 de Janeiro de 1986, que dispõe sobre critérios básicos e diretrizes gerais para a avaliação de impacto ambiental.Diário Oficial [da] República Federativa do Brasil, Brasília, DF, 17 fev. 1986.

BRASIL. Instrução Normativa do IPHAN nº 01 de 25 de Março de 2015, que estabelece procedimentos administrativos a serem observados pelo Instituto do Patrimônio Histórico e. Artístico Nacional nos processos de licenciamento ambiental dos quais participe. Diário Oficial [da] República Federativa do Brasil, Brasília, DF, 26 mar. 2015.

BRASIL. Portaria Interministerial n 69 de 01 de Dezembro de 1989, que aprova as normas comuns sobre pesquisa, exploração, remoção e demolição de coisas ou bens de valor artístico, de interesse histórico ou arqueológico, afundados, submersos, encalhados e perdidos em águas sob jurisdição nacional, em terrenos de marinha e seus acrescidos e em terrenos marginais em decorrência de sinistro, alijamento ou fortuna do mar. Diário Oficial [da] República Federativa do Brasil, Brasília, DF, 23 jan. 1989.

BRASIL. Lei Federal 3.924, de 26 de julho de 1961. Dispõe sobre os monumentos arqueológicos e préhistóricos. Diário Oficial [da] República Federativa do Brasil, Brasília, DF, 27 jul. 1961.

BRASIL. Lei Federal 7.542, de 26 de setembro de 1986. Dispõe sobre a pesquisa, exploração, remoção e demolição de coisas e bens afundados, submersos, encalhados e perdidos em águas sob jurisdição nacional, em terrenos de marinha e seus acrescidos e em terrenos marginais em decorrência de sinistro, alijamento ou fortuna do mar e dá outras providências. Diário Oficial [da] República Federativa do Brasil, Brasília, DF, 26 set. 1986.

BRASIL. Lei Federal 10.166, de 27 de dezembro de 2000. Altera a Lei $\mathrm{n}^{\circ} 7.542$ de 26 de setembro de 1986, que dispõe sobre a pesquisa, exploração, remoção e demolição de coisas e bens afundados, submersos, encalhados e perdidos em águas sob jurisdição nacional, em terrenos de marinha e seus acrescidos e em terrenos marginais em decorrência de sinistro, alijamento ou fortuna do mar e dá outras providências. Diário Oficial [da] República Federativa do Brasil, Brasília, DF, 27dez. 2000. 